\title{
Molar concentration Effects on the Optical and Structural Properties of nanostructural $\mathrm{SnO}_{2}$ Thin Films
}

\author{
Nadir F. Habubi*, Ziad M. Abood, Ahmed N. Algamel \\ Al-Mustansiriyah University, College of Education, Physics department, Baghdad-Iraq \\ *Corresponding author E-mail: nadirfadhil@yahoo.com
}

Keywords: transparent conducting oxide, AFM, SEM, PL, optical properties

\begin{abstract}
Thin films of nanostructured $\mathrm{SnO}_{2}$ with different molarites were prepared by chemical spray pyrolysis technique. XRD analysis reveals that all the films were tetragonal polycrystalline with a preferred orientation along (110) plane. AFM measurements indicate that the value of the grain size for $0.05 \mathrm{M}, 0.1 \mathrm{M}$ and $0.15 \mathrm{M}$ were $111 \mathrm{~nm}, 78 \mathrm{~nm}$ and $58 \mathrm{~nm}$ respectively. SEM micrograph proved the existence of small cracks on the film surface, EDS confirmed the composition percentage ratio of $\mathrm{Sn}$ and $\mathrm{O}_{2}$ and no trace of impurities could be detected. PL spectra gives the indication about optical energy gap and the effect of concentration on it which appeared as a blue shift. The transmittance was studied for the deposited thin films ,identifying that the transmittance decreases by the increase in molarity. The value of the optical energy gap of the deposited thin films was increased upon increasing molar concentration due o quantum confinement effect. The Urbach energy was also studied, their values decrease as the molar concentration increase.
\end{abstract}

\section{Introduction}

Stannic oxide had a considerable attention due to its amazing properties like, eminent chemical stability, high transparency, low resistivity, $\mathrm{SnO}_{2}$ is insulator in its bulk condition, while its shows a semiconductor behavior when prepared as a thin film due to the deviation from stoichiometry result as n-type semiconductor, top most infrared reflectivity, $\mathrm{SnO}_{2}$ posses high electron mobility and wide band gap together with non toxicity and redundancy in nature[1-4]. For these reasons $\mathrm{SnO}_{2}$ was spotlighted in many numerous applications such as potential anode in lithium ion batteries[5], solar cells [6], gas sensors[7,8], varistors[9] and photocatalysis ${ }^{[10]}$.

Various experimental techniques were adopted to fabricate $\mathrm{SnO}_{2}$ thin films depending on kind of application such as, rf sputtering[11], sol-gel[12],pulsed laser deposition[13], successive ionic layer adsorption and reaction SILAR[14], electron beam evaporation technique[15],chemical vapor deposition[16] and spray pyrolysis[17,18]. Spray pyrolysis technique was used in this work to deposit $\mathrm{SnO}_{2}$ thin films onto quartz substrates with different concentrations and study the effect of molarity on the structural, morphological and optical properties of nanostructure $\mathrm{SnO}_{2}$ thin films.

\section{Experimental details}

Thin films of $\mathrm{SnO}_{2}$ have been prepared by chemical spray pyrolysis technique. Aqeous solution of $\mathrm{SnCl}_{4} .5 \mathrm{H}_{2} \mathrm{O}$ with different molarties $(0.05,0.1,0.15 \mathrm{M})$ was used as a source of $\mathrm{Sn}$, Quartz substrates were used to deposit $\mathrm{SnO}_{2}$.After many trials, the following conditions was chosen in order to obtain homogenous films, pinhole free, well adherent to substrates. These conditions arrived at the follwing: substrate temperature was $500{ }^{\circ} \mathrm{C}$ and was kept constant during the deposition process, distance between substrate and nozzlewas $28 \mathrm{~cm}$, spraying time was $10 \mathrm{~S}$ lasted by 90 to obviate immoderate cooling, depostion rate was $4 \mathrm{ml} / \mathrm{min}$. nitrogen was used as a gas carrier.

The thickness of the film was measured by gravimetric method and was in the range of $300 \mathrm{~nm}$ Structural properties were carried out using X-Ray Diffraction Technique (shimadzu - XRD6000, shimadzu company /Japan. Morphological properties were accomplished by Jeol JSM-6335F scanning electron microscope equipped with (EDAX). Topographical was achieved by atomic force 
microscopy (AFM) Nasoscope III and Dimension 3100. Photoluminescence and the transition energy of the samples were measured using the (ELICO, SL174, spectroflurometer, Xe Lamp Power Supply). Transmittance and absorbance were measured by using a double beam spectrophotometer (Schimadzu 1650 UV probe Japan) in the wavelength range (350-1100)nm. All the measurements were achieved at room temperature .

\section{Results and discussion}

The XRD Patterns recorded for molar concentration of $\mathrm{SnO}_{2}$ thin films are shown in Fig. (1). Utilizing the JCPDS data card no. 41-1445, these films were found to be of cassisterite type with a tetragonal structure. The main diffraction peaks attributed to (110),(101), (200), and (211) of $\mathrm{SnO}_{2}$ these peaks indicate the polycrystallanity of these films, have a preferred orientation along (110) which remains prevalent irrespective of the molar concentration . Small peaks were shown in 0.05 $\mathrm{M}$ and $0.1 \mathrm{M}$ and vanish when we reached $0.15 \mathrm{M}$. The lattice constant values for $\mathrm{a}_{\mathrm{o}}$ and $\mathrm{c}_{\mathrm{o}}$ were tabulated in Table 1, these values were in good agreement with the data obtained by JCPDS data card no. (41-1445). The average crystallite size was calculated using Scherrer formula for different molarties and was found to decrease as the molar concentration increase as can be seen from Table 1.Texture coefficient[19] was calculated for the deposited thin film, their values were shown in Table 1 indicating unequivocally that the preferred orientation is along(110). The number of crystallite per unit area and the dislocation density[20] were obtained also. Their values were listed in Table 1 showing increase as the concentration increased.

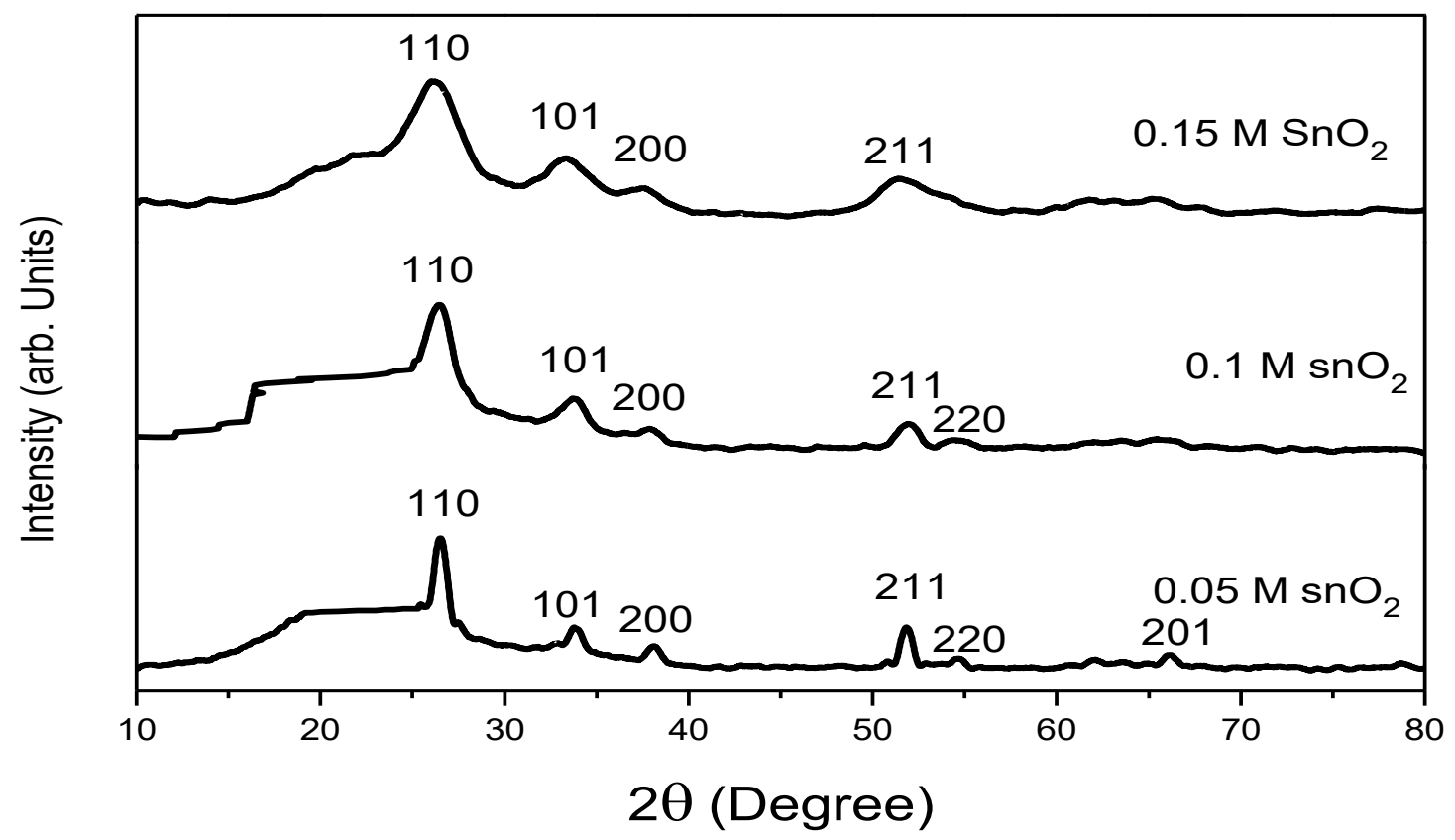

Fig. $1 \mathrm{XRD}$ patterns for different molarties of $\mathrm{SnO}_{2}$ thin films 
Table 1 Dtructural parameters for different molarties of $\mathrm{SnO}_{2}$ thin films

\begin{tabular}{|c|c|c|c|c|c|c|c|}
\hline molarity & $\mathrm{a}_{\mathrm{o}}(\AA)$ & $\mathrm{c}_{\mathrm{o}}(\AA)$ & Strain & $\mathrm{D}_{\mathrm{av}}(\mathrm{nm})$ & $\mathrm{T}_{\mathrm{C}}$ & $\begin{array}{c}\text { No of crystallites } \\
\text { /unit area }\left(\mathrm{m}^{-2}\right) \mathrm{x} \\
10^{18}\end{array}$ & $\begin{array}{c}\text { Dislocation } \\
\text { density } /\left(\mathrm{m}^{-2}\right) \mathrm{x} \\
10^{16}\end{array}$ \\
\hline 0.05 & 4.741 & 3.190 & -0.094 & 21 & 1.32 & 0.0378 & 0.226 \\
\hline 0.1 & 4.767 & 3.182 & 0.156 & 6 & 1.71 & 1.6200 & 2.700 \\
\hline 0.15 & 4.769 & 3.225 & -1.192 & 4 & 1.51 & 5.4600 & 6.250 \\
\hline
\end{tabular}

Fig. 2 depicts the AFM images $(0.125 \times 0.125) \mu \mathrm{m}$ with Granularity Cumulation Distribution Report of $\mathrm{SnO}_{2}$ with a different morality grown on quartz substrate this measurement was performed near the center region of the deposited thin films. It can be seen that by increasing the molarity the grain size decrease. wo mechanisms control the kinetic grain growth these are ripening and coalescence, ripening responsible for the reduction of surface to bulk ratio, while coalescence deals with the combination of two small grains with the same size to merge into larger grain[21]. AFM measurements indicated that the surface roughnes and RMS roughness were smooth, the film with $0.1 \mathrm{M}$ was smoother than the $0.05 \mathrm{M}$ and $0.15 \mathrm{M}$. The values of roughness average, RMS roughness and grain size were listed in Table 2.

Table 2 AFM Parameters ( roughness average, RMS roughness and grain size)

\begin{tabular}{|c|c|c|c|}
\hline Molarity & Roughness average $(\mathrm{nm})$ & RMS roughness $(\mathrm{nm})$ & Grain size $(\mathrm{nm}$ \\
\hline 0.05 & 1.810 & 2.110 & 111 \\
\hline 0.1 & 0.485 & 0.565 & 78 \\
\hline 0.15 & 1.400 & 1.300 & 58 \\
\hline
\end{tabular}

Fig. 3 represent the SEM micrograph of $\mathrm{SnO}_{2}$ thin films with different molarity concentrarion prepared by spray pyrolysis . no evidence of well crystalline can be observed, these results were in good agreement with Patil et al. [22], but it can be seen that better crystallinity in comparsion between the variation of molarity was presented in Fig.1-a and Fig 1-b ,while Fig 1-c show small cracks on the film surface which might be due to the variation of expansion and intrinsic stress [23]. Table 3 shows the composition percentage of Oxygen and Tin, no other contribution of impurities was detected. EDS were secure to get information concerning the film composition[24].EDS analysis disclose the oxygen/tin atomic ratio, their values were $2.597,1.4271$ and 0.792 for $0.05 \mathrm{M}$, $0.1 \mathrm{M}, 0.15 \mathrm{M}$ respectively.

Fig. 4 shows the PL spectra which were measured at room temperature of $\mathrm{SnO}_{2}$ prepared with different concentrations. The peak of $(0.05 \mathrm{M})$ was around $320 \mathrm{~nm}$ is very broad and was shifted toward lower wavelength (blue shift) as the molar concentration increase due to quantum confinement effects. 

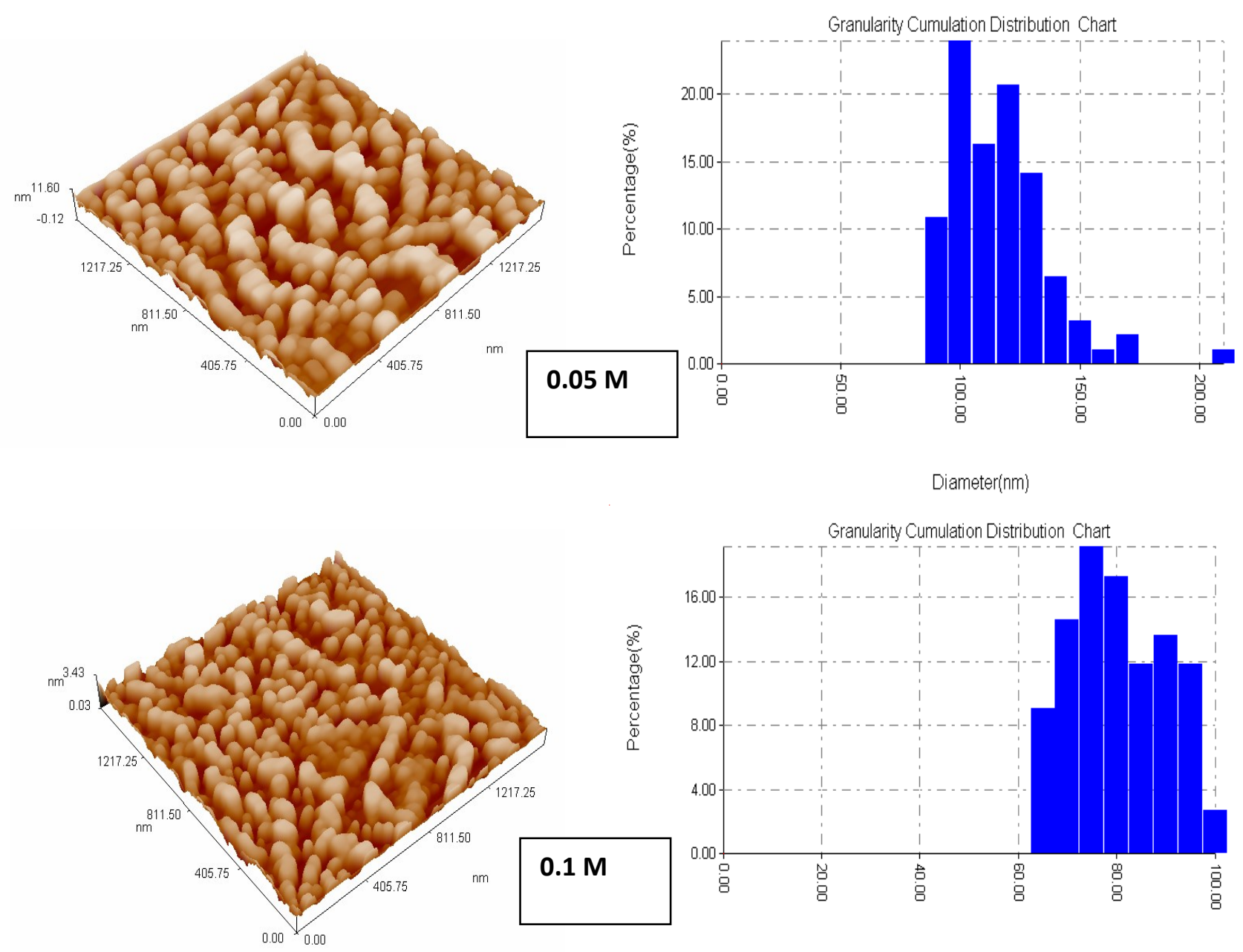

Diameter(nn)

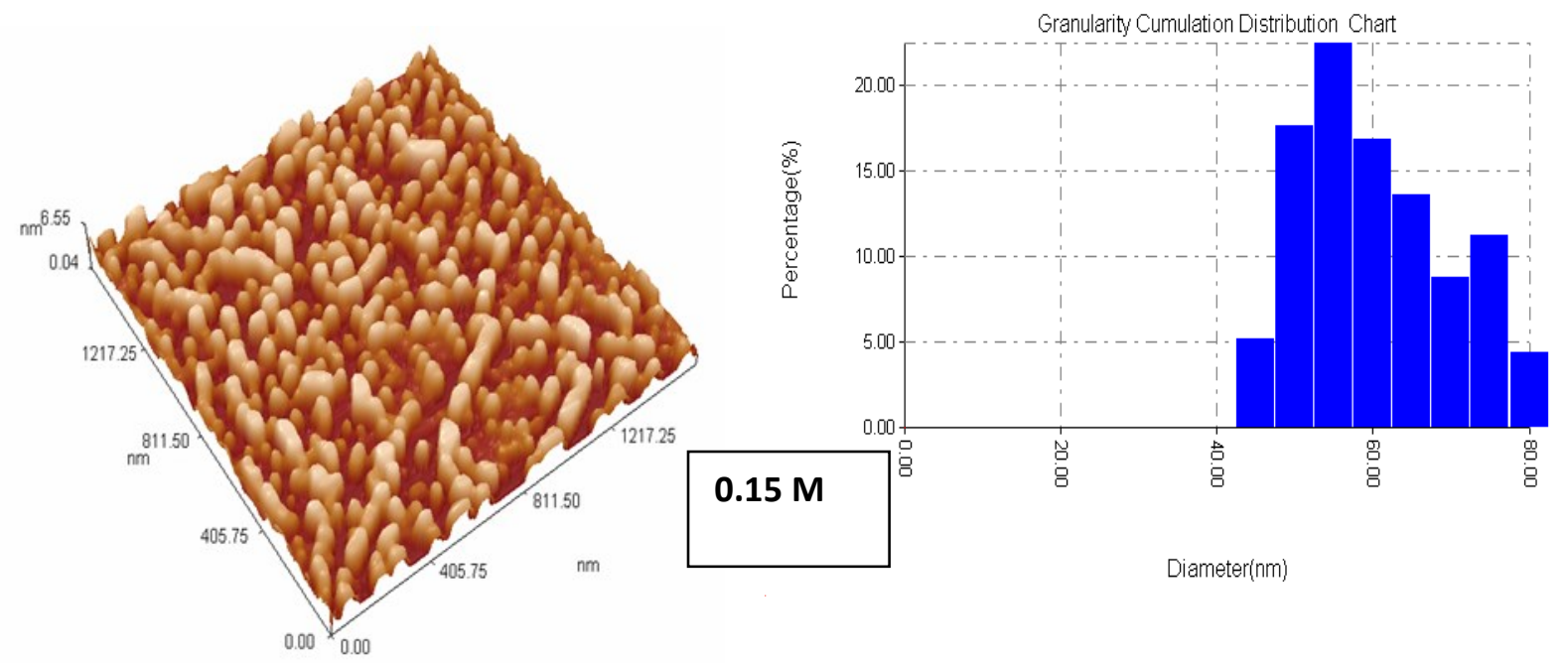

Fig. 2 AFM Topogragh and Granularity Cumulation Distribution of $\mathrm{SnO}_{2}$ with different molarties 
(a)

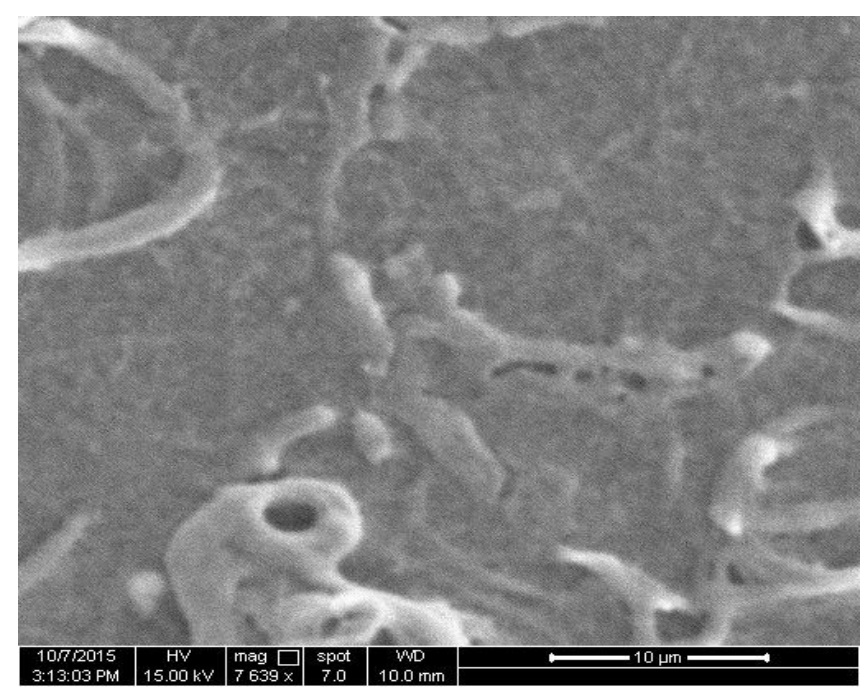

(b)

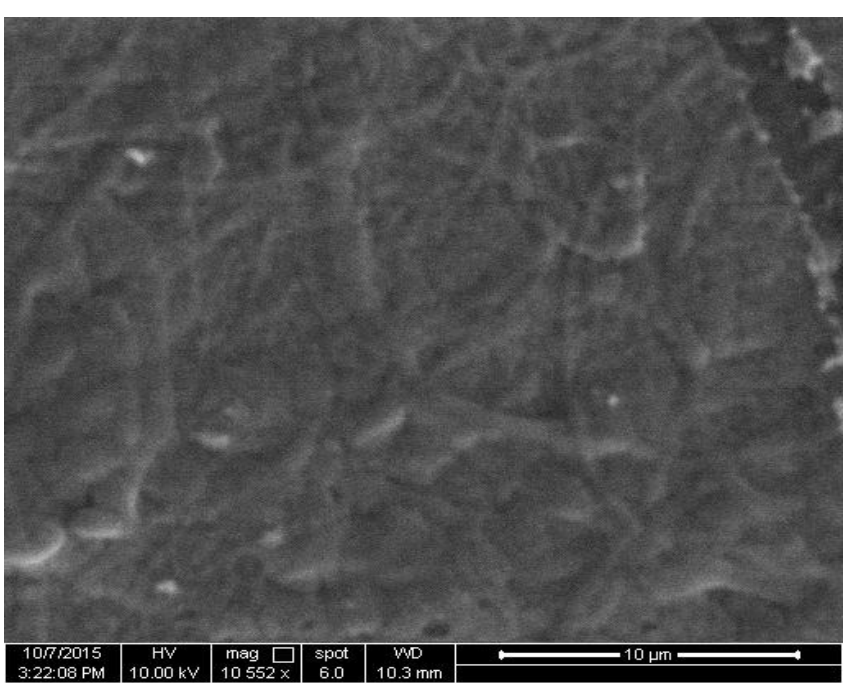

(c)

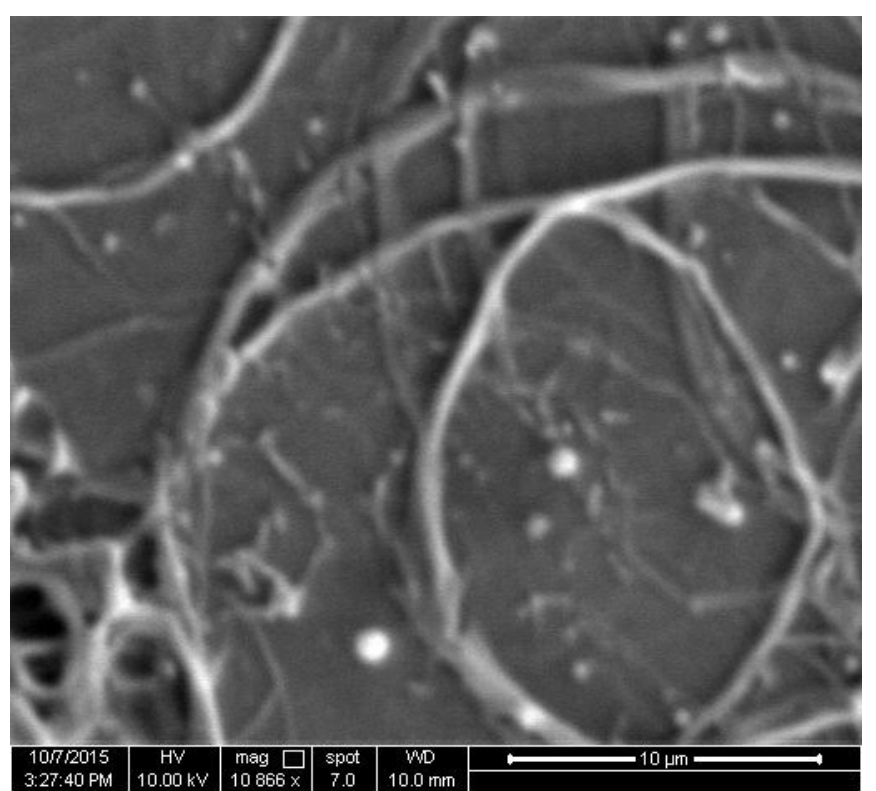

Fig. 3 SEM photograph of different molarity for $\mathrm{SnO}_{2}$ thin films (a) $0.05 \mathrm{M}$ (b)0.1M (c)0.15M

Table 3 EDS contribution of $\mathrm{SnO}_{2}$ with different molar concentration

\begin{tabular}{|c|c|c|}
\hline molarity & Oxygen \% & Tin \% \\
\hline 0.05 & 66.93 & 25.77 \\
\hline 0.10 & 58.80 & 41.20 \\
\hline 0.15 & 44.19 & 55.81 \\
\hline
\end{tabular}




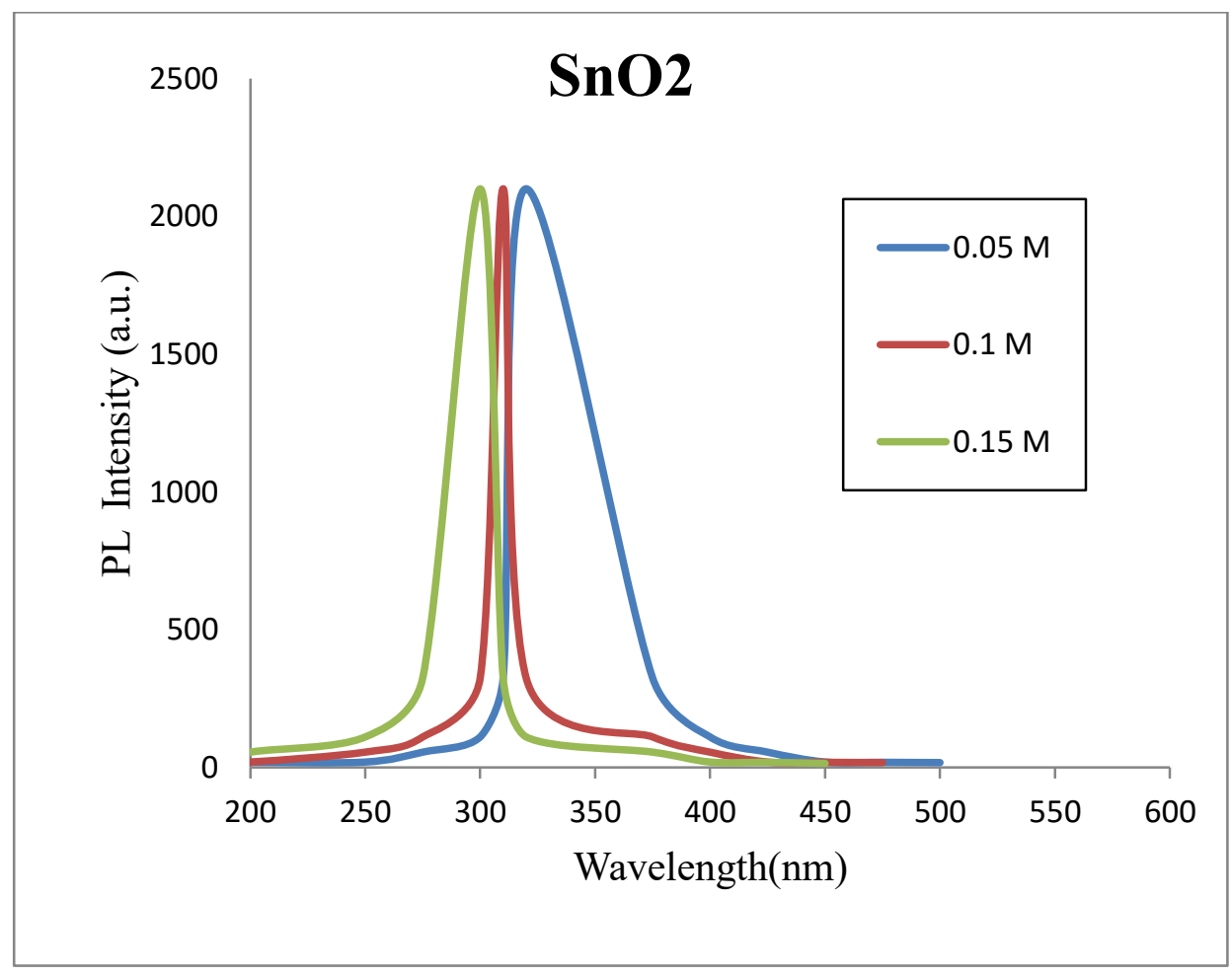

Fig. 4 PL spectra of $\mathrm{SnO}_{2}$ with different molar concentration at room temperature.

The optical transmittance spectra of $\mathrm{SnO}_{2}$ prepared with different molar concentration were shown in Fig 5 . From this figure, it can be recognized that the increase in molar concentration has scored in a decrease in transmittance. A decrease in the transmittance of $\mathrm{SnO}_{2}$ thin film might be due to an increase in light scattering by defect on the surface of the film, the surface of the thin film creates a defect state with oxygen deficiencies which reduce the crystal size[24,25]. The average transmittance at $550 \mathrm{~nm}$ was $66.77,62.89,49.18$ for $0.05 \mathrm{M}, 0.1 \mathrm{M}$ and $0.15 \mathrm{M}$ respectively

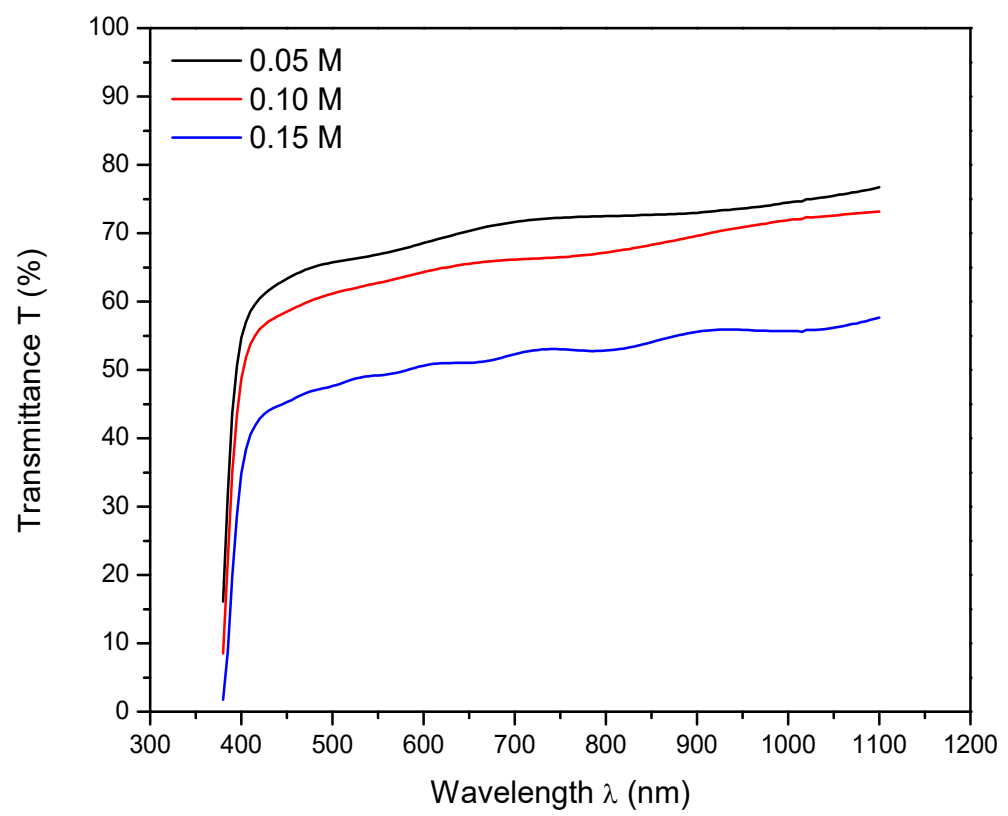

Fig. 5 Transmittance versus wavelength of the as deposited $\mathrm{SnO}_{2}$ thin films 
Fig. 6 depicts the relation between the absorbance and wavelength, it can be seen that there is a shift in the absorption edge toward shorter wavelengths ( blue shift) this blue shift can be attributed to the quantum confinement[26,27]. It has believed that the absorbance is molarity dependence.

The value of the optical energy gap can be estimated by Tauc formula [28] according to the following relation

$$
(\alpha h v)=A\left(h v-E_{g}\right)^{r}
$$

Where $\alpha$ represent the absorption coefficient, $h v$ is the photon energy, $E_{g}$ is the optical energy gap , while $\mathrm{A}$ is constant which depends on reduced mass, , refractive index and speed of light[29]. As we observe that $\mathrm{SnO}_{2}$ thin film was exist in tetragonal structure only and because of the sharpness of the absorption edge which, shows linearity against energy for the as deposited films[30]. The extrapolation of the linear part can be useful in determining the optical energy gap as shown in Fig.7, the value of the optical energy gap was estimated to be increased as the concentration increase because of the quantum confinement effect. This behavior is in good agreement with Varnamkhasti et al: [31].

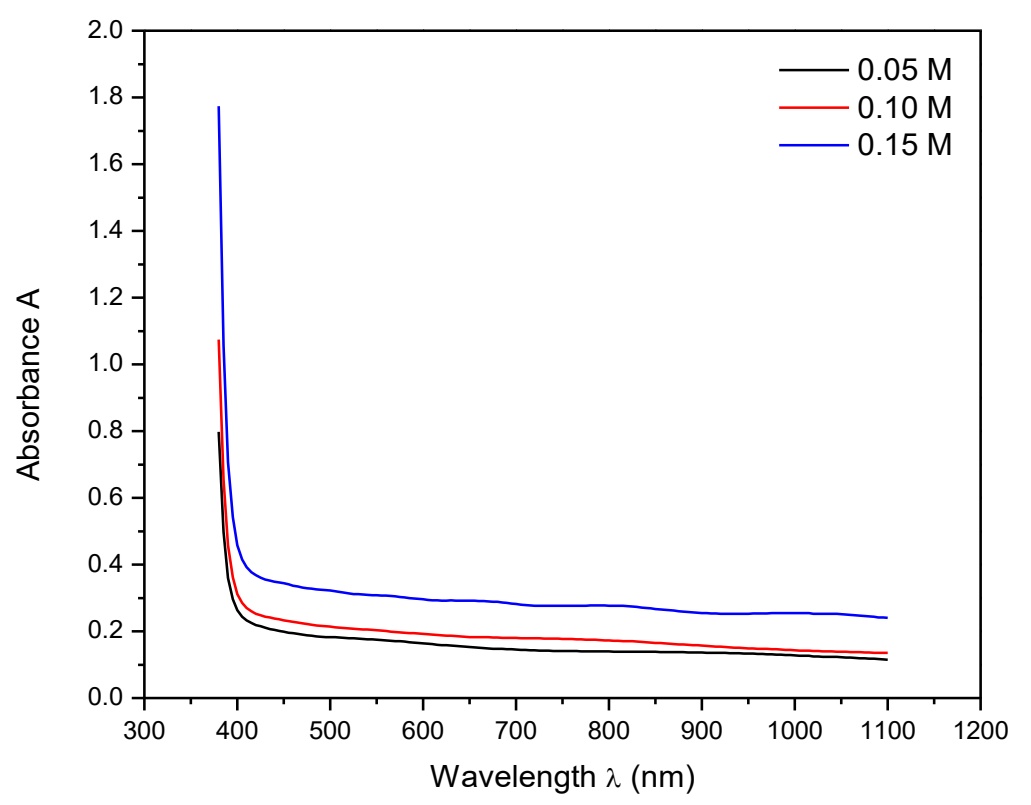

Fig. 6 Absorbance versus wavelength for the as deposited thin films 


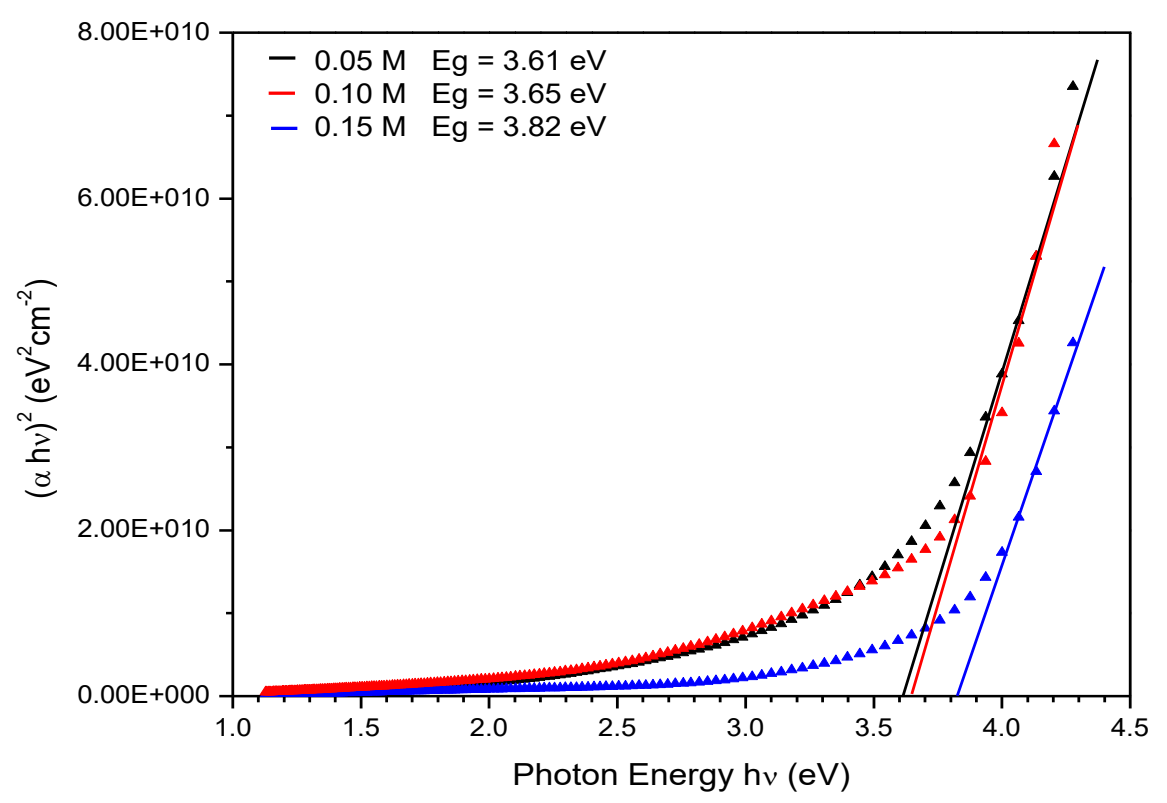

Fig, $7(\alpha h v)^{2}$ versus photon energy for the as deposited thin films with different concentration The value of Urbach tail of the $\mathrm{SnO}_{2}$ thin films can be estimated from the known relation [32]:

$$
\alpha=\alpha_{o} \exp \left(\frac{E}{E_{U}}\right)
$$

Where $\mathrm{E}_{\mathrm{U}}$ represents the width of the exponential absorption edge, $\mathrm{E}$ is the photon energy, and $\alpha_{0}$ is constant. Fig 8 shows the relation between $\ln (\alpha)$ as a function of photon energy so, the Yrbach energy was calculated from the inverse of the slope, it can be seen from the results that $E_{U}$ decrease with increase of concentration, showing an inverse relation with the optical energy gap. These results were in good agreement with Rahal et al. [33].

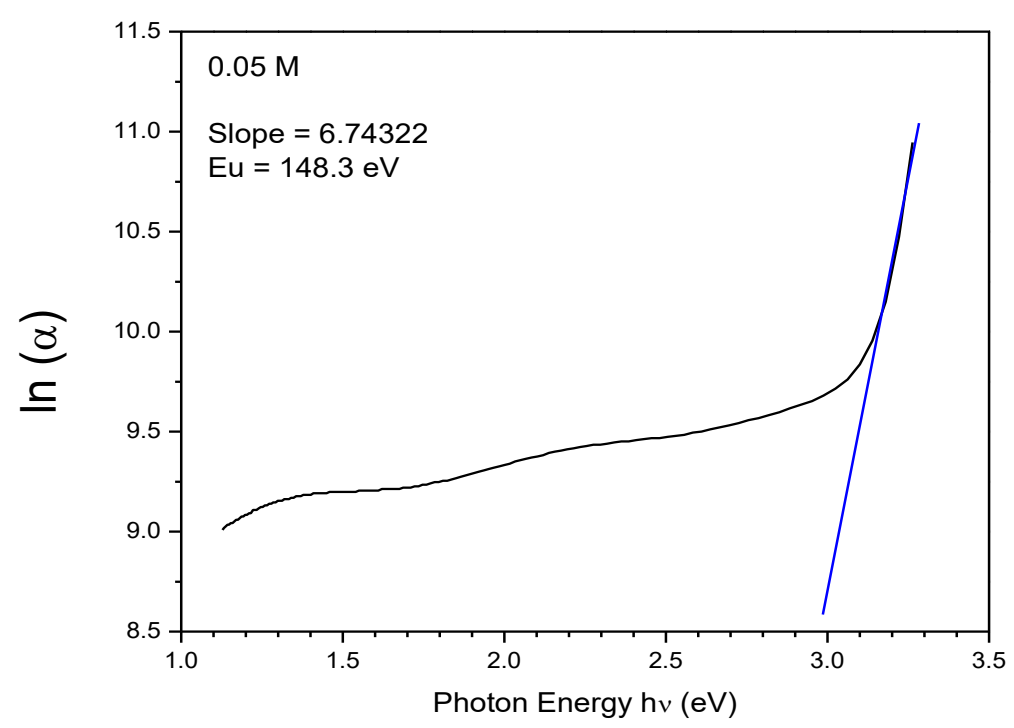



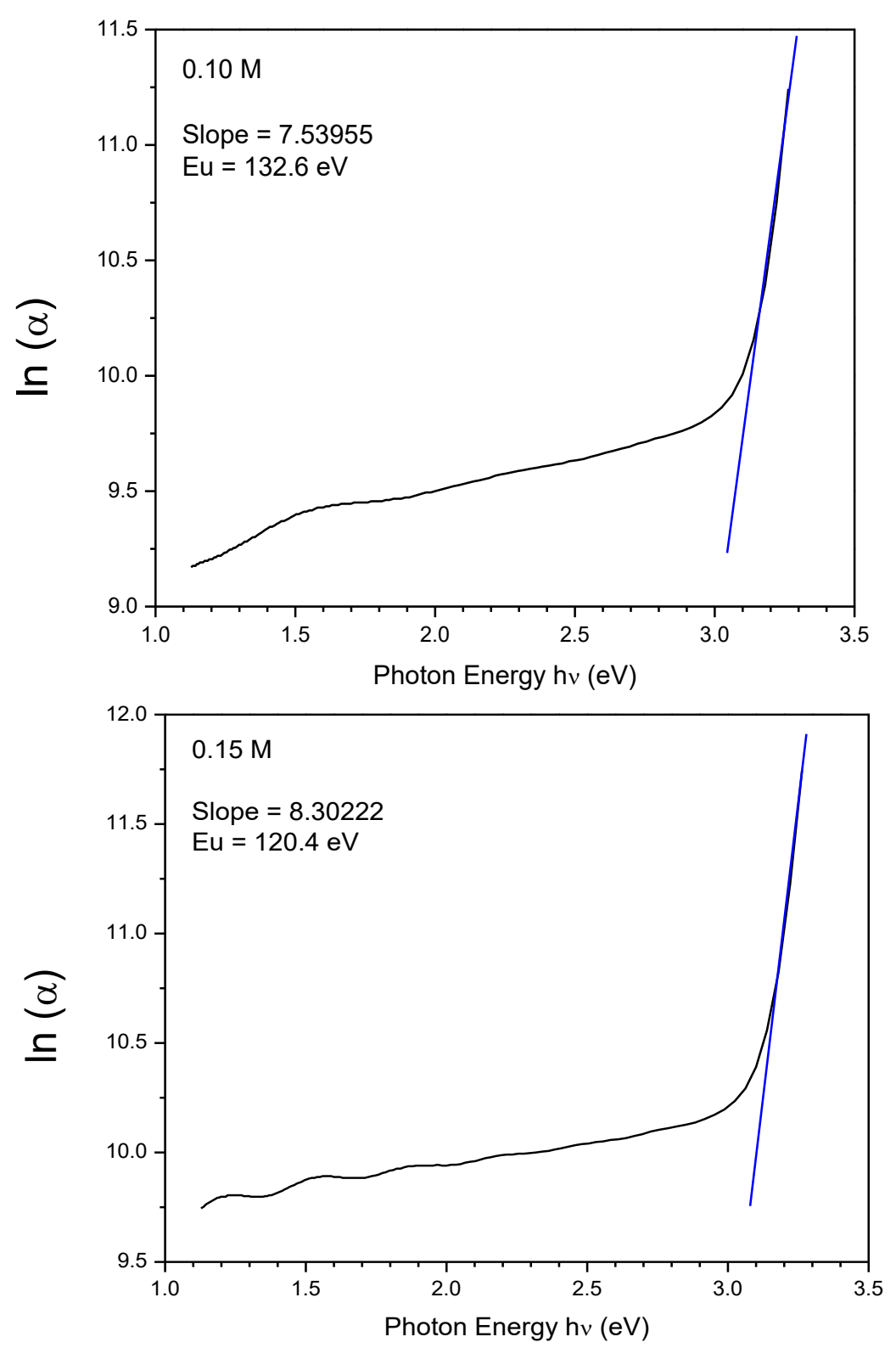

Fig. $8 \ln (\alpha)$ versus photon energy for the as deposited thin films with different concentrations

\section{Conclusions}

The effect of different molar concentration was studied successfully . XRD anaylyses show that all he deposited thin films were polycrystalline. The average crystallite size obtains by Scherrer formula gave an indication about the location of nanostructure. AFM micrograph confirm the existence of nanostructure with a value that decrease as the molar concentration increase the optical energy gap was estimated showing an increase in its value as the molar concentration increase and this because of the quantum confinement effect. 


\section{References}

[1] E. Elangovan, K. Ramamurthi , A study on low cost-high conducting fluorine and antimonydoped tin oxide thin films, Applied Surface Science 249 (2005) 183-196.

[2] A.V. Moholkar, S.M. Pawar, K.Y. Rajpure, C.H. Bhosale, Effect of concentration of $\mathrm{SnCl}_{4}$ on sprayed fluorine doped tin oxide thin films, Journal of Alloys and Compounds 455 (2008) 440446.

[3] M. Ait Aouaj, R. Diaz , A. Belayachi , F. Rueda, M. Abd-Lefdil , Comparative study of ITO and FTO thin films grown by spray pyrolysis ,Materials Research Bulletin 44 (2009) 1458-1461.

[4] E. Çetinörgü , S. Goldsmith , R.L. Boxman, Effect of deposition conditions on the characteristics of $\mathrm{ZnO}-\mathrm{SnO}_{2}$ thin films deposited by filtered vacuum arc, Thin Solid Films $\mathbf{5 1 5}$ (2006) 880-884 .

[5] J. Santos-Pena, T. Rousse , L. anchez, J. Morales and D. M. chleich , Antimony doping effect on the electrochemical behavior of $\mathrm{SnO}_{2}$ thin film electrodes ,Journal of Power Sourses 9798(2001) 232-234

[6] D.W. Sheel , H.M. Yates , P. Evans, U. Dagkaldiran , A. Gordijn , F. Finger, Z. Remes , and M. Vanecek, Atmospheric pressure chemical vapour deposition of $\mathrm{F}$ doped $\mathrm{SnO}_{2}$ for optimum performance solar cells, Thin Solid Films 517 (2009) 3061-3065.

[7] Sardar M. Ayub Durrani, Biasing voltage dependence of sensitivity of electron beam evaporated $\mathrm{SnO}_{2}$ thin film CO sensor, Sensors 6 (2006) 1153-1160.

[8] Biplob Mondala, Borat Basumataria, Jayoti Das, Chirosree Roychaudhury, Hiranmay Saha, Nillohit Mukherjee, $\mathrm{ZnO}-\mathrm{SnO}_{2}$ based composite type gas sensor for selective hydrogen sensing, Sensors and Actuators B ,194 (2014) 389-396.

[9] S.A. Pianaro , P.R. Bueno, E. Longo, J.A. Varela , Microstructure and electric properties of a $\mathrm{SnO}_{2}$ based varistor,Ceramics International 25 (1999) 1-6.

[10] $\mathrm{G}$ Mandal and $\mathrm{T}$ Ganguly, Applications of nanomaterials in the different fields of photosciences, Indian J. Phys. 85 (2011)1229-1245.

[11] Jun-Bo Han, Hui-Jun Zhou, Qu-Quan Wang, Conductivity and optical nonlinearity of Sb doped $\mathrm{SnO}_{2}$ films, Materials Letters 60 (2006) 252 - 254.

[12] Sk. F. Ahmed, S. Khan, P. K. Ghosh, M. K. Mitra, K. K. Chattopadhyay, Effect of Al doping on the conductivity type inversion and electro-optical properties of $\mathrm{SnO}_{2}$ thin films synthesized by sol-gel technique, Journal of Sol-Gel Science and Technology 9 (2006) 241-247.

[13] M. Gaidi,A. Hajjaji,R. Smirani, B. Bessais and M. A. El Khakani, Structure and photoluminescence of ultrathin films of $\mathrm{SnO}_{2}$ nanoparticles synthesized by means of pulsed laser deposition, Journal of Applied Physics 108 (2010) 063537 -5.

[14] P. Mitra and S. Mondal, Hydrogen and LPG sensing properties of $\mathrm{SnO}_{2}$ films obtained by direct oxidation of SILAR deposited SnS, Bulletin of The Polish Academy of Sciences 56(2008) 295-300.

[15] V. Senthilkumar, P. Vickraman, Structural, optical and electrical studies on nanocrystalline tin oxide $\left(\mathrm{SnO}_{2}\right)$ thin films by electron beam evaporation technique Journal of Materials Science: Materials in Electronics 21 (2010) 578-583.

[16] M. Maleki, S. M. Rozati, An economic CVD technique for pure $\mathrm{SnO}_{2}$ thin films deposition: Temperature effects, Bulletin of Materials Science 36 (2013) 217-221.

[17] Patrick Mwathe, Robinson Musembi, Mathew Munji, Victor Odari, Lawrence Munguti , Alex Ntilakigwa, John Nguu and Boniface Muthoka, Effect of Surface Passivation on Electrical Properties of Pd-F: $\mathrm{SnO}_{2}$ Thin Films Prepared by Spray Pyrolysis Technique, Coatings 4 (2014) 747-755. 
[18] Yoon Ho Cho, Xishuang Liang, Yun Chan Kang, Jong-Heun Lee, Ultrasensitive detection of trimethylamine using $\mathrm{Rh}$-doped $\mathrm{SnO}_{2}$ hollow spheres prepared by ultrasonic spray pyrolysis, Sensors and Actuators B 207(2015)330-227.

[19] Mujdat Caglar a, Saliha Ilican, Yasemin Caglar, Fahrettin Yakuphanoglu, Electrical conductivity and optical properties of $\mathrm{ZnO}$ nanostructured thin film, Applied Surface Science 255 (2009) 4491-4496.

[20] R.R. Kasar, N.G. Deshpande, Y.G. Gudage, J.C. Vyas, Ramphal Sharma, Studies and correlation among the structural, optical and electrical parameters of spray-deposited tin oxide $\left(\mathrm{SnO}_{2}\right)$ thin films with different substrate temperatures, Physica B 403 (2008) 3724-3729.

[21] H. Yana , G.H. Chen, W.K. Man, S.P. Wong, R.W.M. Kwok, Characterizations of $\mathrm{SnO}_{2}$ thin films deposited on Si substrates, Thin Solid Films 326 (1998) 88-91.

[22] P.S. Patila, R.K. Kawar, T. Seth, D.P. Amalnerkar, P.S. Chigare , Effect of substrate temperature on structural, electrical and optical properties of sprayed tin oxide $\left(\mathrm{SnO}_{2}\right)$ thin films Ceramics International 29 (2003) 725-734.

[23] Daoli Zhang, Zhibing Deng, Jianbing Zhang, Liangyan Chen, Microstructure and electrical properties of antimony-doped tin oxide thin film deposited by sol-gel process Materials Chemistry and Physics 98 (2006) 353-357.

[24] D. Maestre, A. Cremades, J. Piqueras, Direct observation of potential barrier formation at grain boundaries of $\mathrm{SnO}_{2}$ ceramics, Semicond. Sci. Technol. 19 (2004) 1236-2239.

[25[ M.-M. Bagheri-Mohagheghi, N. Shahtahmasebi, M.R. Alinejad, A. Youssefi, M. ShokoohSaremi, Fe-doped $\mathrm{SnO}_{2}$ transparent semi-conducting thin films deposited by spray pyrolysis technique: thermoelectric and p-type conductivity properties, Solid State Sciences 11 (2009) 233239.

[26] Chang Q Sun, T P Chen, B K Tay, S Li, H Huang, Y B Zhang, L K Pan, S P Lau and X W Sun, An extended quantum confinement 'theory: surface-coordination imperfection modifies the entire band structure of a nanosolid, J. Phys. D: Appl. Phys. 34 (2001) 3470-3479.

[27] Panagiotis Poulopoulos, Bjo" rn Lewitz, Andreas Straub, Spiridon D. Pappas, Sotirios A. Droulias, Sotirios Baskoutas, and Paul Fumagalli , Band-gap tuning at the strong quantum confinement regime in magnetic semiconductor EuS thin films, Applied Physics Letters 100 (2012) $211910-4$.

[28] J. Tauc, in: F. Abele's (Ed.), Optical Properties of Solid, Elsevier, Amsterdam, 1971, pp. 277.

[29] Ebru S,enadım Tu“zemen, Sitkı Eker, Hamide Kavak, Ramazan Esen, Dependence of film thickness on the structural and optical properties of $\mathrm{ZnO}$ thin films, Applied Surface Science 255 (2009) 6195-6200.

[30] Nese Kavasoglu, A. Sertap Kavasoglu, Metal-semiconductor transition in undoped ZnO films deposited by spray pyrolysis, Physica B 403 (2008) 2807-2810.

[31] Mohsen Ghasemi Varnamkhasti, Hamid Reza Fallah, Mehdi Zadsar, Effect of heat treatment on characteristics of nanocrystalline $\mathrm{ZnO}$ films by electron beam evaporation, Vacuum 86 (2012) 871-875.

[32] F. Urbach, The long-wavelength edge of photographic sensitivity and of the electronic absorption of solids, Phys. Rev. 92 (1953) 1324.

[33] Achour Rahal1, Said Benramache and Boubaker Benhaoua, The effect of the film thickness and doping content of $\mathrm{SnO}_{2}: \mathrm{F}$ thin films prepared by the ultrasonic spray method, Journal of Semiconductors 34 (2013) 093003-5. 